\title{
Antimicrobial Resistance in Commensal Escherichia coli Isolated from Pigs and Pork Derived from Farms Either Routinely Using or Not Using In-Feed Antimicrobials
}

\author{
Kittitat Lugsomya, Jitrapa Yindee,, Waree Niyomtham, Chanwit Tribuddharat, \\ Padet Tummaruk, David J. Hampson, ${ }^{4,5}$ and Nuvee Prapasarakul ${ }^{1,6}$
}

The aims of this study were (i) to evaluate whether routine in-feed antimicrobial use in pigs or not resulted in differences in antimicrobial resistance (AMR) E. coli at different pig producing stages, and (ii) to determine whether resistant strains were presented in pig meat postslaughter. A total of 300 commensal E. coli isolates were obtained and examined for antibiograms, AMR genes, plasmid replicons, and molecular types. The isolates were from two farms either using (A) or not using in-feed antimicrobials (NA), sampled four times during the production cycle and once postslaughter. E. coli resistant to aminoglycosides containing aadAl, $a a d A 2$, and $a a d B$ and extended-spectrum beta-lactamase-producing (ESBLP) E. coli containing bla $a_{\mathrm{CTX}-\mathrm{M}-1}$ were significantly increased in the nursery and growing periods in farm A compared to farm NA. IncI1-I $\gamma$ and IncHI2 were common in the nursery period and were shown to transfer bla $a_{\mathrm{CTX}-\mathrm{M}}$ genes by conjugation. ST10 was the most common type only found in live pigs. ST604, ST877, ST1209, and ST2798 ESBLP were found only in live pigs, whereas ST72, ST302, and ST402 ESBLP were found in pig meat.

Keywords: antimicrobial resistance, Escherichia coli, extended-spectrum beta-lactamese-producing Escherichia coli, longitudinal study, pig production, pork

\section{Introduction}

$\mathbf{T}$ HE ONGOING INCREASE in antimicrobial resistance $(\mathrm{AMR})$ in enteric bacteria in production animals and their potential transmission to humans represent a major threat to public health. ${ }^{1}$ Commensal enteric bacteria such as Escherichia coli (E. coli), which reside for prolonged periods in the intestinal tract, potentially represent an important reservoir of AMR in the food chain, and moreover they make good representative markers for investigating dynamic changes in AMR genes. ${ }^{2}$ Even though the source of AMR has not always been identified using molecular epidemiological analysis or DNA-based data, bacteria from livestock are believed to be a major source of AMR in the environment, and resistant bacteria and resistance genes may be acquired by the human gut microbiome. ${ }^{3}$
Some contract pig-rearing farms in Thailand routinely use antimicrobials under veterinary prescription as feed additives for prophylaxis against bacterial infections and/or as growth promoters. This use is problematic as it is increasingly understood that imprudent application of antimicrobials during the production cycle may increase the occurrence of AMR bacteria on farms, especially during the immediate postweaning "nursery" period. ${ }^{4}$ To date, most studies have only involved cross-sectional observations taken at specific periods of production, with the studied farms having a lack of availability of historical data about antimicrobial use. ${ }^{5}$ A more holistic understanding should result from longitudinal surveillance at different points through the production cycle to meat at slaughter, especially if exposure or lack of exposure to antimicrobials can be recorded. Such studies should indicate the likelihood of transmission of AMR bacterial from

\footnotetext{
${ }^{1}$ Department of Veterinary Microbiology, Faculty of Veterinary Science, Chulalongkorn University, Bangkok, Thailand.

${ }^{2}$ Department of Microbiology, Faculty of Medicine Siriraj Hospital, Mahidol University, Bangkok, Thailand.

${ }^{3}$ Department of Obstetrics Gynaecology and Reproduction, Faculty of Veterinary Science, Chulalongkorn University, Bangkok, Thailand.

${ }^{4}$ School of Veterinary and Life Sciences, Murdoch University, Perth, Australia.

${ }^{5}$ College of Veterinary and Life Sciences, City University of Hong Kong, Kowloon Tong, Hong Kong SARS.

${ }^{6}$ Diagnosis and Monitoring of Animal Pathogens Research Unit, Chulalongkorn University, Bangkok, Thailand.
}

(C) Kittitat Lugsomya et al., 2018; Published by Mary Ann Liebert, Inc. This Open Access article is distributed under the terms of the Creative Commons License (http://creativecommons.org/licenses/by/4.0), which permits unrestricted use, distribution, and reproduction in any medium, provided the original work is properly cited. 
animals on the farm to the product, and hence to the consumer. $^{5}$

The aims of this study were (i) to look for alterations in AMR and characteristics of commensal E. coli isolated from cohorts of pigs sampled at different phases during the production cycle on farms, which either were routinely using or not using in-feed antimicrobials, and (ii) to look for similarities between $E$. coli contaminating pig meat and those recovered from the same pigs on the two farms.

\section{Materials and Methods}

\section{Farms}

The study was undertaken at two multisite industrial pig farms from Nakhon Pathom and Chainart Provinces, respectively, both of which were run following the Thai standard livestock farm criteria under the guidance of the Department of Livestock Development. These were designated farm A (using antibiotics) and farm NA (not using antibiotics). In farm A in Nakhon Pathom, a combination of tiamulin and amoxicillin at $100 \mathrm{ppm}$ and $250 \mathrm{ppm}$, respectively, were routinely mixed into the feed during the postweaning nursery and growing periods. In farm NA located in Chainart, antimicrobials had not been used as a feed additive for over 10 years. Enrofloxacin injections were used in the case of symptomatic bacterial infections in the preweaning period; however; all such treated pigs were excluded from this study. Both farms had over 1,000 sows, had no pig replacement from outside sources, used an all-in all-out production system, and had consistent management for at least 2 years in terms of antimicrobial use and sanitary and biosecurity measures taken. The farms were well managed and kept good records of production and antimicrobial use. On farm A, antimicrobial use was withdrawn at least 30 days before the pigs were slaughtered.

\section{Animal selection and timing of sampling}

For each farm, one healthy pig from each of ten different litters was selected for use in the experiment (a total 10 pigs per group). Each pig was ear tagged and sampled at five periods up to and including postslaughter: the neonatal period (at 5 days of age); the postweaning nursery period (at 8 weeks of age); the growing period (at 14 weeks of age); the finishing period (at 24 weeks of age, just before transport to the abattoir); and following slaughter at the abattoir. None of the pigs showed signs of ill health as judged by weekly routine clinical inspection by veterinarians and the farmer's daily observations, nor did they receive therapeutic antimicrobials during the production cycle. The pigs from the two farms were killed at two different abattoirs.

\section{Sample collection and bacterial identification}

The sampling protocol was approved by the Chulalongkorn University Animal Care and Use Committee (permit number 58/2558). For the pigs in the neonatal and nursery periods, rectal swabs were taken directly and kept in Clary-Blair transport medium. For pigs in the growing and finishing periods, at least $25 \mathrm{~g}$ of rectal feces were collected into sterile plastic containers. For the pigs at the abattoir, meat ("pork") was sampled and placed into sterile containers. Following routine abattoir processing by abattoir staff, half carcasses were suspended on hooks before being moved for subsequent retail sale. A sterile scalpel blade was used to excise at least $25 \mathrm{~g}$ of meat from the biceps femoris muscle from a cross-section of the previously opened thigh area of each hanging half-carcass. All samples were delivered to the laboratory at $4^{\circ} \mathrm{C}$ within 24 hours. The rectal swabs were suspended in $0.85 \%$ sodium chloride solution (NSS) and directly spread on Eosin Methylene Blue (EMB) (Oxoid) agar. ${ }^{6}$ For rectal feces, at least $5 \mathrm{~g}$ was diluted 10 -fold to $10^{-4}$ and the solutions plated to EMB agar. One gram of each meat sample was placed in a sterile plastic bag with $9 \mathrm{~mL}$ of sterile normal saline and blended in a stomacher (Interscience Malaysia) for 3 minutes. After vigorously shaking, $100 \mu \mathrm{L}$ of the suspension was spread on EMB agar. ${ }^{7}$ All plates were incubated overnight at $37^{\circ} \mathrm{C}$. For each sampling time for each animal, three representative colonies from the highest dilution plate were selected for further characterization. Colonies presenting a metallic sheen on EMB plates were selected and confirmed as E. coli by their IMViC biochemical reactions, comprising an indole test. ${ }^{8}$

\section{Antibiogram and extended-spectrum beta-lactamase phenotype confirmation}

The basic procedures followed have been described previously. ${ }^{9}$ The minimal inhibitory concentration of antimicrobials for $E$. coli were determined using the AST-GN 38 test kit in the Vitek2 compact automated susceptibility level detection apparatus (BioMérieux, France). The 18 antimicrobials or combination of antimicrobials used were as follows: amikacin (AK: 2-64 $\mu \mathrm{g} / \mathrm{mL}$ ), amoxicillin (AMX: 2-32 $\mu \mathrm{g} / \mathrm{mL}$ ), amoxicillin/ clavulanic acid (AMC: $2 / 1-32 / 16 \mu \mathrm{g} / \mathrm{mL}$ ), ampicillin (AMP: 2-32 $\mu \mathrm{g} / \mathrm{mL}$ ), cefalexin (CEX: 4-64 $\mu \mathrm{g} / \mathrm{mL}$ ), cefpirome (CPR: $2-16 \mu \mathrm{g} / \mathrm{mL}$ ), cefpodoxime (CPD: $0.25-8 \mu \mathrm{g} / \mathrm{mL}$ ), ceftiofur (XNL: $1-8 \mu \mathrm{g} / \mathrm{mL}$ ), chloramphenicol (C: $2-64 \mu \mathrm{g} / \mathrm{mL}$ ), enrofloxacin (ENR: $0.125-4 \mu \mathrm{g} / \mathrm{mL}$ ), gentamicin (GEN: $2-$ $64 \mu \mathrm{g} / \mathrm{mL}$ ), imipenem (IMP: $1-16 \mu \mathrm{g} / \mathrm{mL}$ ), marbofloxacin (MBRL: $0.5-4 \mu \mathrm{g} / \mathrm{mL}$ ), nitrofurantoin (NIT: $16-512 \mu \mathrm{g} / \mathrm{mL}$ ), piperacillin (PIP: 4-128 $\mu \mathrm{g} / \mathrm{mL}$ ), tetracycline (TET: 1-16 $\mu \mathrm{g} /$ $\mathrm{mL}$ ), tobramycin (TOB: $4-16 \mu \mathrm{g} / \mathrm{mL}$ ), and trimethoprim/sulfamethoxazole (SXT: 1/19-16/304 $\mu \mathrm{g} / \mathrm{mL}$ ). E. coli ATCC 25922 was used as the control strain. The interpretation of the susceptibility levels for AMP, CPD, CPR, XNL, GEN, ENR, MBR, and TET was performed following the Clinical Laboratory Standards (CLSI) for antimicrobial disks and testing for bacteria isolated from animals (VET2-0S3) ${ }^{10}$ and interpretation for AMX, PIP, AMC, CEX, IMP, AK, TOB, NIT, and SXT was followed according to the CLSI standards for antimicrobial susceptibility testing (M100-S25). ${ }^{11}$

\section{Extended-spectrum beta-lactamase phenotypic screening and confirmatory test}

Extended-spectrum beta-lactamase-producing (ESBLP) E. coli were identified using the Vitek2 machine (BioMérieux, France $)^{12}$ and the results were confirmed by the combination disk test following CLSI standards recommendations. ${ }^{11}$ The $b l a_{\text {СТХ-M }}$ genes comprising variants $b l a_{\text {СТХ-М-1 }}, b l a_{\text {СTX-M-2, }}$ $b l a_{\mathrm{CTX}-\mathrm{M}-8}, b l a_{\mathrm{CTX}-\mathrm{M}-9}$, and $b l a_{\mathrm{CTX}-\mathrm{M}-25 / 26}$ were detected by multiplex PCR in all ESBLP strains. ${ }^{13}$ The identity of representative PCR amplicons was confirmed by DNA sequencing 
and analyzed using Mega $7.0,{ }^{14}$ with comparisons made to the GenBank database.

To confirm whether $b l a_{\mathrm{CTX}-\mathrm{M}}$ genes were located on transmissible plasmids, a conjugation assay was performed using the broth mating technique, as previous described. ${ }^{15}$ The three representative selected donor clones, E. coli PCU12-4 (positive for bla $_{\mathrm{CTX}-\mathrm{M}-1}$ group with a single IncI1-I $\gamma$ replicon), E. coli PCU12-5 (positive for bla ${ }_{\text {CTX-M-1 }}$ group with a single IncHI2 replicon), and PCU12-6 (positive for $b l a_{\mathrm{CTX}-\mathrm{M}-9}$ group with a single IncHI2 replicon), were selected. The recipient strain E. coli J53 was resistant to sodium azide $\left(\mathrm{Azi}^{\mathrm{r}}\right)$ and susceptible to cefotaxime. The transconjugants were selected on Luria-Bertani (LB) agar (Oxoid) supplemented with cefotaxime $\left(2 \mu \mathrm{g} \mathrm{mL}^{-1}\right)$ and sodium azide $\left(100 \mu \mathrm{g} \mathrm{mL}^{-1}\right)$ (Oxoid). Testing for antimicrobial susceptibility, ESBL confirmatory phenotype, PCR detection, and DNA sequencing of $b l a_{\mathrm{CTX}-\mathrm{M}}$ genes was performed on the transconjugants, as previously described. ${ }^{15}$

\section{Detection of genes encoding AMR}

DNA was extracted from the bacteria using a Wizard ${ }^{\circledR}$ Genomic DNA Purification Kit (Promega, Germany). Sixteen pairs of primers that were specific for resistance genes in bacteria in the superfamily Enterobacteriaceae were generated (First Base Laboratories, Malaysia), and the PCR thermal cycling conditions used followed previous recommendations. The resistance genes analyzed included $b l a_{\mathrm{TEM}}$ and $b l a_{\mathrm{PSE}-1}$ for ampicillin, amoxicillin, and piperacillin resistance, aadA 1 and $\operatorname{aadA} 2$ for streptomycin resistance, $a a d B$ for tobramycin and gentamicin resistance, tet $(\mathrm{A})$ and $\operatorname{tet}(\mathrm{B})$ for tetracycline resistance, sul1, sul2, and sul3 for sulfonamide resistance, $d f r A 1$, $d f r A 10$, and $d f r A 12$ for trimethoprim resistance, and catA, catB, and $c m l A$ for chloramphenicol resistance. ${ }^{16}$ The bla $_{\mathrm{CTX}-\mathrm{M}-1}$ group, bla $a_{\mathrm{CTX}-\mathrm{M}-2}$ group, bla $a_{\mathrm{CTX}-\mathrm{M}-8}$ group, bla $a_{\mathrm{CTX}-\mathrm{M}-9}$ group, and bla $a_{\mathrm{CTX}-\mathrm{M}-25,26}$ group were included as these are the most prevalent ESBLP encoding genes. ${ }^{13}$ A representative positive PCR amplicon for each gene was submitted for DNA sequencing and was analyzed by MEGA $7.0 .^{14}$

\section{Plasmid Replicon Characterization}

The Enterobacteriaceae plasmid replicons IncF (IncFIA, IncFIB, IncFIC, and IncFrep), IncI1-I $\gamma$, IncN, IncP, IncW, IncHI1, IncHI2, IncL/M, IncT, IncA/C, IncK, IncB/O, IncX, and IncY were detected using five multiplex and three simplex PCR tests. The primers, PCR conditions, and thermal cycles were as previously described. ${ }^{17}$ Representative positive PCR amplicons for each replicon were submitted for DNA sequencing and analyzed as described above.

\section{Pulsed-Field Gel Electrophoresis}

Pulsed-field gel electrophoresis (PFGE) was performed on the $300 \mathrm{E}$. coli isolates following the CDC standard protocol. ${ }^{18}$ Briefly, E. coli DNA in agar plugs was digested with restriction enzyme XbaI (Sibenzyme, Russia). Gel electrophoresis was undertaken in a $200 \mathrm{~V}$ field at $120^{\circ}$ for 18-19 hours, incorporating Salmonella serovar Braenderup H9812 DNA as a standard. Dendrograms were generated using the GeneTool program (Syngene, India) and analyzed with the GeneDirectory program (Syngene, India).

\section{Multilocus Sequence Typing}

The sequence types (ST) of the $300 \mathrm{E}$. coli isolates were obtained based on the allelic profiles of seven genes with "'housekeeping" function. ${ }^{19}$ STs were obtained using highthroughput multilocus sequence typing (HiMLST) (Boers et al., 2012). ${ }^{20}$ The target genes were amplified by a two-step PCR using a primer sequence for the target genes that included a universal tail sequence primer and an isolate-specific multiplex identifier sequence primer with 454 sequencingspecific nucleotides at the $5^{\prime}$ end. The PCR products were pooled, clonally amplified by emulsion PCR (emPCR) (Roche, Switzerland), and sequenced using the GS junior (Roche). Allele and sequence types (STs) were assigned by the publicly accessible E. coli MLST database at http:// mlst.warwick.ac.uk/mlst/dbs/Ecoli.

\section{Data Analysis}

Within each farm, comparisons between the rates of the categorical variables (resistance; replicon detection; and resistance gene profiles) of the $E$. coli isolates were made between successive sampling times (i.e., results from the 30 isolates from the neonatal period compared to the 30 from the postweaning period and the 30 from the postweaning period compared to the 30 from the grower period). Betweenfarm comparisons were made for the 30 isolates at each sampling time for each variable. Results were analyzed using the chi-square test in SPSS version 17.0 (IBM, Armonk, NY). Isolates that were resistant to at least three antimicrobial groups were defined as being multidrug resistant (MDR). The molecular strain types (PFGE profiles and STs) were individually reported by descriptive analysis. The Shannon diversity index $\left(H^{\prime}\right)$ was performed to determine the genetic diversity of the $E$. coli strains between farms and was calculated according to the following formula:

$$
H^{\prime}=-\sum_{i=0}^{s} p_{i} \ln p_{i}
$$

$\mathrm{S}$ was the number of unique genotype; and $\mathrm{p}_{\mathrm{i}}$ was the number of isolates sharing the same PFGE profiles [i] over the total number of isolates. ${ }^{21}$

\section{Results}

\section{Phenotypic resistance characterizations and extended-spectrum beta-lactamase phenotype confirmation}

A total of 300 commensal $E$. coli isolates were analyzed (3 per pig at each sampling period, 150 per farm). The AMR profiles for the 300 isolates against 18 antimicrobials and their ESBLP profile are shown in Fig. 1. Resistance to nearly all the antimicrobials was common. All or nearly all isolates at all sampling periods (including in pork) from pigs in both farms were resistant to the $\beta$-lactam group antibiotics (ampicillin, amoxicillin, and piperacillin), and to tetracycline. Statistically significant differences in resistance rates and ESBLP phenotype between sampling periods were 

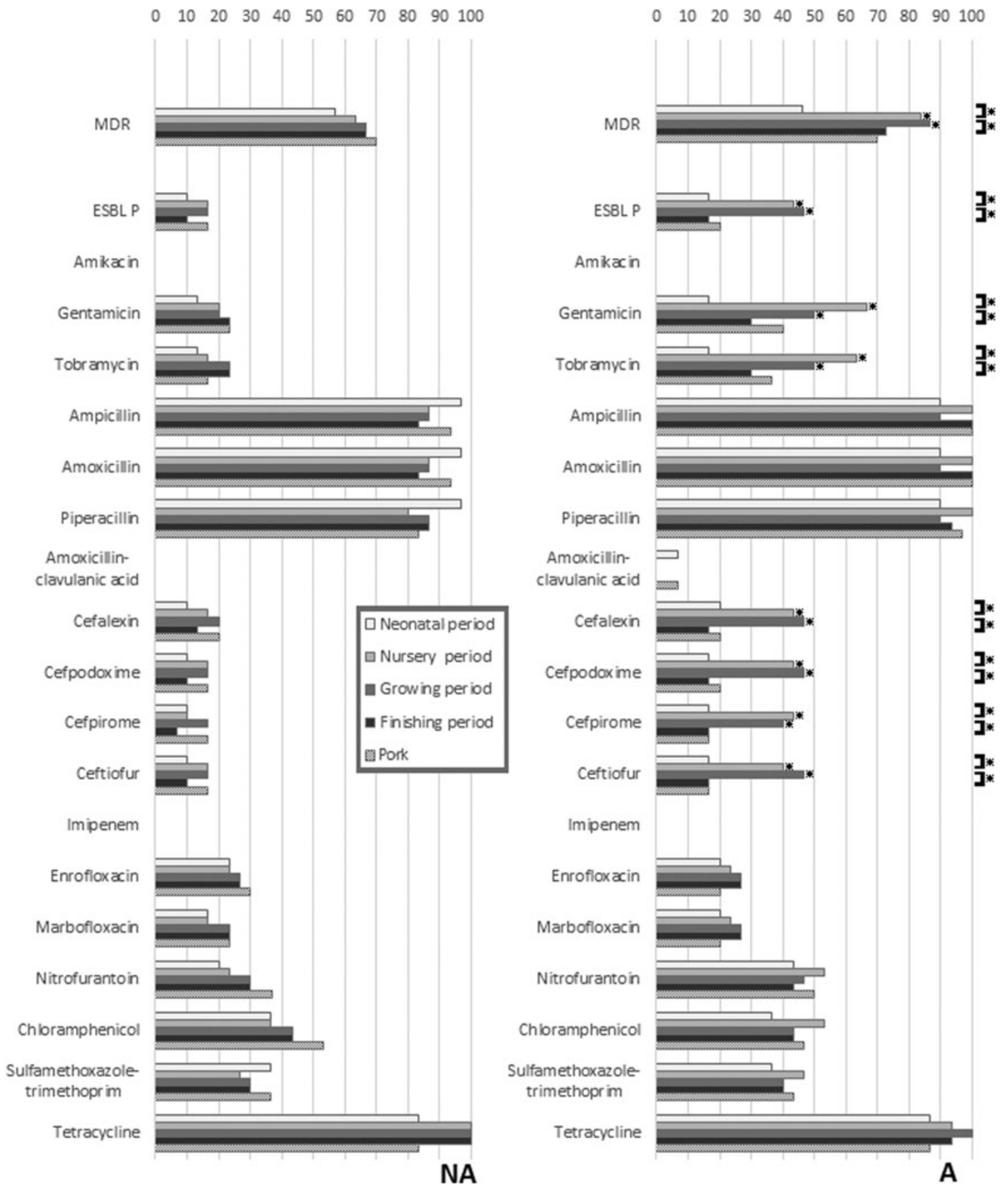

FIG. 1. Differences in resistance rates to 18 antimicrobials and ESBLP in Escherichia coli isolated from pigs in different periods of the production cycle and postslaughter (pig meat), with comparisons between isolates from the farm using antibiotics (A) and the farm not using antibiotics (NA). *Indicates a significant difference $(p<0.05)$ using chi-squared analysis $(p<0.05)$. Comparisons are made between farms at each sampling period, and within farms at successive sampling periods. ESBLP, extended-spectrum beta-lactamase producing.

only found on farm A, and only for a few antimicrobials (gentamicin, tobramycin, cefalexin, cefpodoxime, cefpirome, ceftiofur, and ESBLP E. coli), with, in each case, the highest rates being in the nursery and grower periods. These same resistances were also statistically significantly higher in the nursery and grower periods in the pigs from farm A compared to those from farm NA. Isolates with MDR phenotypes were common in both farm A $(73.3 \%)$ and farm NA $(64.7 \%)$. The most common AMR pattern, AMP-AMX-PIP-
TET, was detected at $18.0 \%$ and $14.7 \%$ for the isolates from farms NA and A, respectively.

\section{Genotypic resistance characterizations}

The occurrence of 21 genes linked to AMR in the 300 E. coli isolates is depicted in Fig. 2. All, but four of the resistance genes were found in some of the isolates. The most common combined resistance gene pattern $\left[b l a_{\mathrm{TEM}}\right.$ 


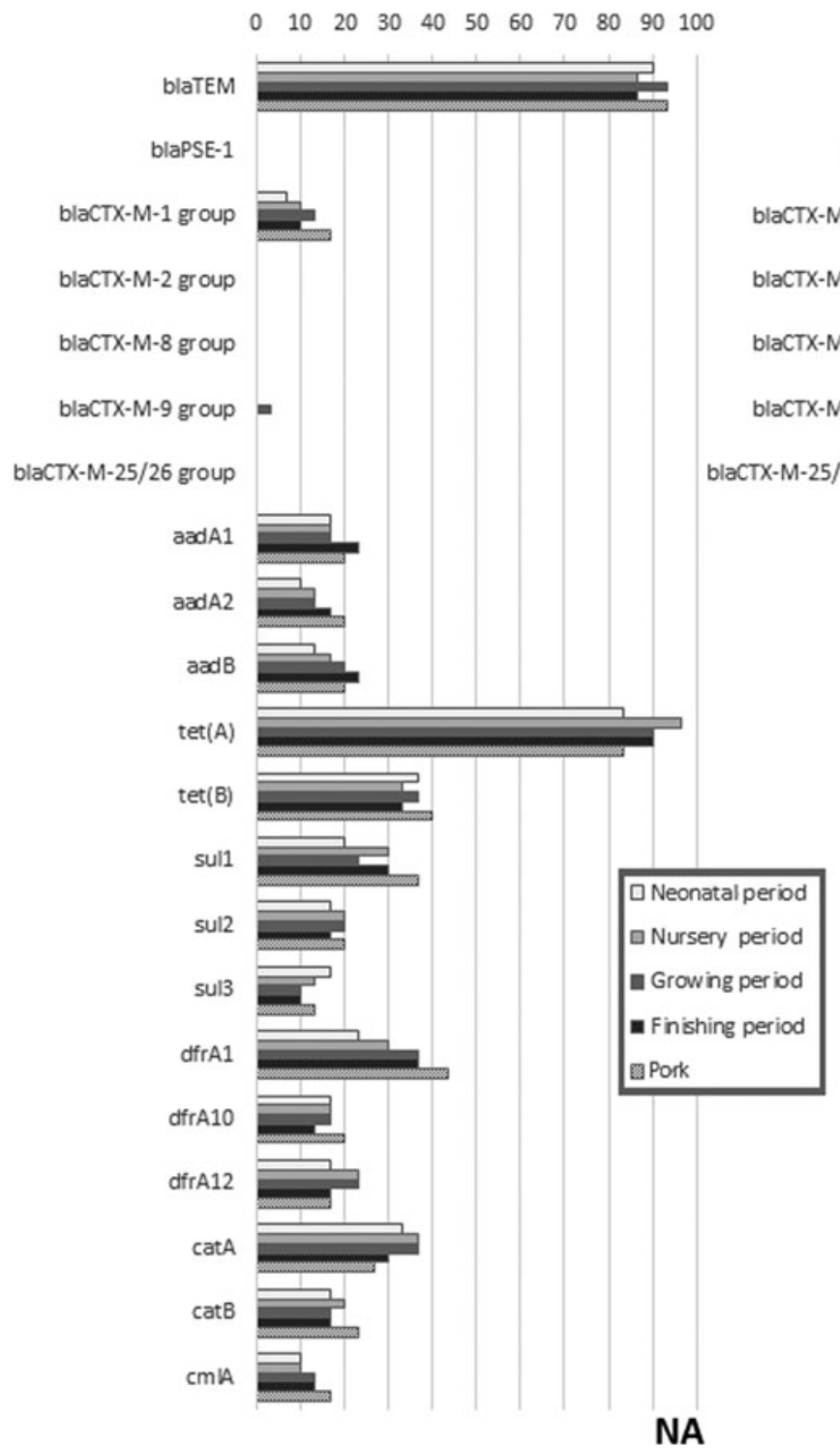

$\begin{array}{lllllllllll}0 & 10 & 20 & 30 & 40 & 50 & 60 & 70 & 80 & 90 & 100\end{array}$

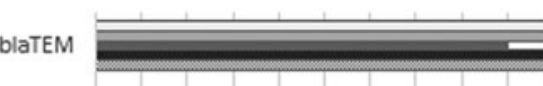

IaPSE-1

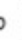

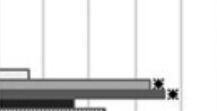

J

adA2

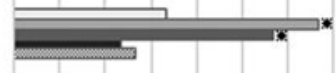

aadA2

$\operatorname{aadB}$

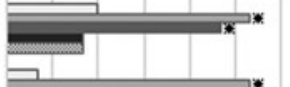

를

tet(A)

$\operatorname{tet}(B)$

sul1

sul2

sul3

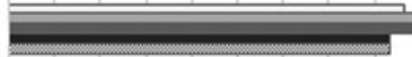

3:

j*

j*

NA

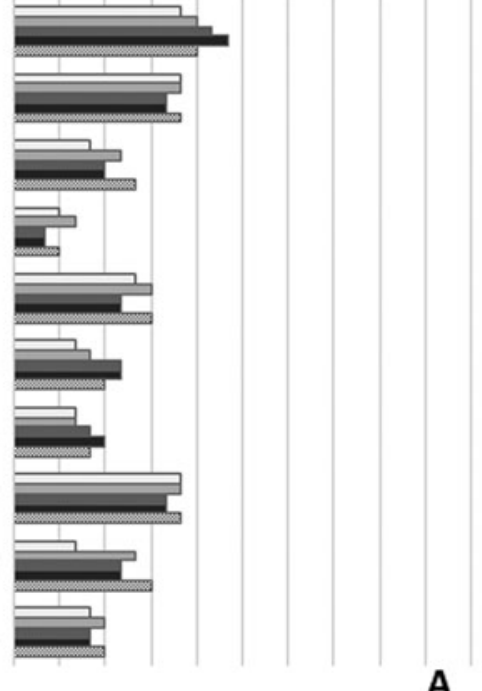

FIG. 2. Differences in 20 antimicrobial resistance genes in E. coli from pigs in different periods of the production cycle and postslaughter (pig meat), with comparisons between the farm using in-feed antibiotics (A) and the farm not using antibiotics (NA). *Indicates a significant difference $(p<0.05)$ using chi-squared analysis $(p<0.05)$. Comparisons are made between farms at each sampling period, and within farms at successive sampling periods.

and tet(A)] was found in both the NA (18.7\%) and the A farm $(14.0 \%)$. Most AMR genes occurred in less than half the isolates at all sampling periods, except for bla $a_{\mathrm{TEM}}$ and tet(A) that were found among nearly all E. coli from both farms. Statistically significant differences in rates at different sampling times were only found in farm A, and only for the $b_{\text {CTX-M-1 }}$ group, aadA1, aadA2, and $a a d B$, where rates were highest in the nursery and growing periods. Statistically significant differences in rates between farms were only found for these same four genes, and only in the nursery and grower periods, where rates were higher in farm A.

\section{Replicon type detection and conjugation experiment}

The prevalence of 18 plasmid replicon types detected in the E. coli isolates is presented in Fig. 3. Replicons IncA/C,
IncB/O, IncFIIA, IncK, IncL/M, IncP, IncT, and IncX were not detected. The IncFIB and IncFrep replicons were the only ones commonly found in both farms. All the other replicon types were found at a low to moderate prevalence in both farms. Statistically significant differences between sampling times were only found on farm A, and these were for IncHI-2 and IncI1-I $\gamma$, which were increased in the isolates from the nursery and grower periods compared to other periods. These two replicons also were statistically significantly more frequently found in isolates from farm A than in isolates from farm NA in both the nursery and grower periods.

In the conjugation assay, E. coli PCU12-4 (positive for $b l a_{\mathrm{CTX}-\mathrm{M}-1}$ group with a single IncI1-I $\gamma$ replicon) transferred bla $a_{\text {CTX-M-1 }}$ group with a frequency of $3.8 \times 10^{-5}$, while E. coli PCU12-5 (positive for bla $a_{\mathrm{CTX}-\mathrm{M}-1}$ group with a single 


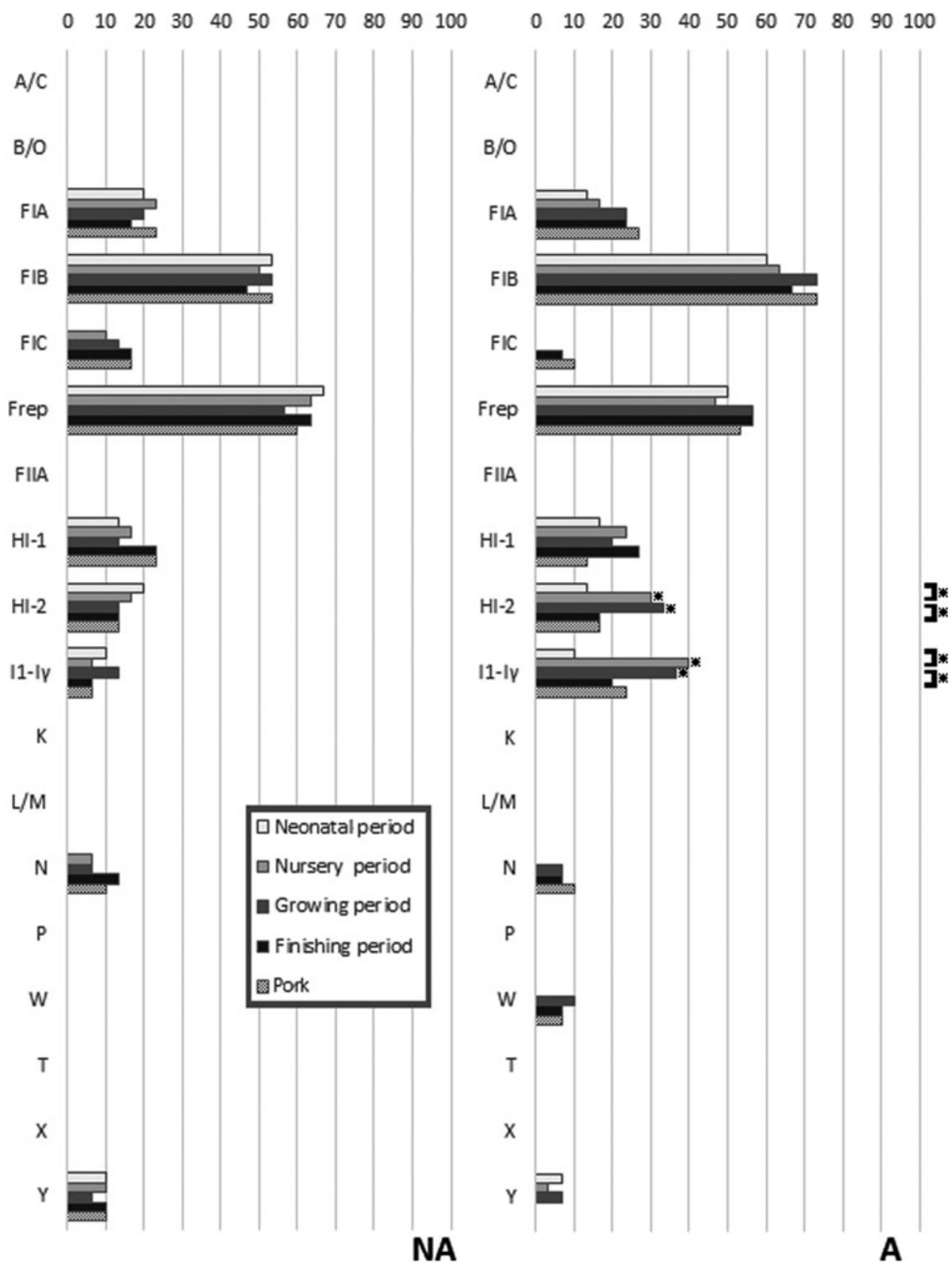

FIG. 3. Differences in carriage of 18 plasmid replicons in E. coli from pigs in different periods of the production cycle and postslaughter (pork) between the farm using in-feed antibiotics (A) and the farm not using antibiotics (NA). *Indicates a significant difference using chi-squared analysis $(p<0.05)$. Comparisons are made between farms at each sampling period, and within farms at successive sampling periods.

IncHI2 replicon) and E. coli PCU12-6 (positive for bla $a_{\text {CTX-M-9 }}$ group with a single IncHI2 replicon) transferred the lla $_{\mathrm{CTX}-\mathrm{M}}$ gene with frequencies of $4.1 \times 10^{-6}$ and $5.6 \times 10^{-6}$, respectively, confirming the location of the genes on these conjugative plasmids.

\section{Molecular genotypic characterizations}

The 300 isolates had diverse molecular types: those from farm A belonged to 25 STs and 43 PFGE types, while those from farm NA belonged to 24 STs and 55 PFGE types. A total of 41 STs were detected, and only nine were shared by isolates from the two farms. No PFGE types were shared between the two farms. Strain diversity (as assessed by comparing PFGE types using the Shannon diversity index) was higher on farm NA $\left(H^{\prime}=3.38\right)$ than on farm A $\left(H^{\prime}=3.31\right)$. PFGE typing was more discriminatory than MLST for identification of individual strains, but both methods gave broadly similar results in terms of depicting relationships between isolates (Fig. 4). In the case of three pigs, one or two isolates recovered from pork shared the same molecular types and resistance profiles with those recovered from the feces of the corresponding live animal at earlier periods: this occurred in one pig on farm NA (ST44) 


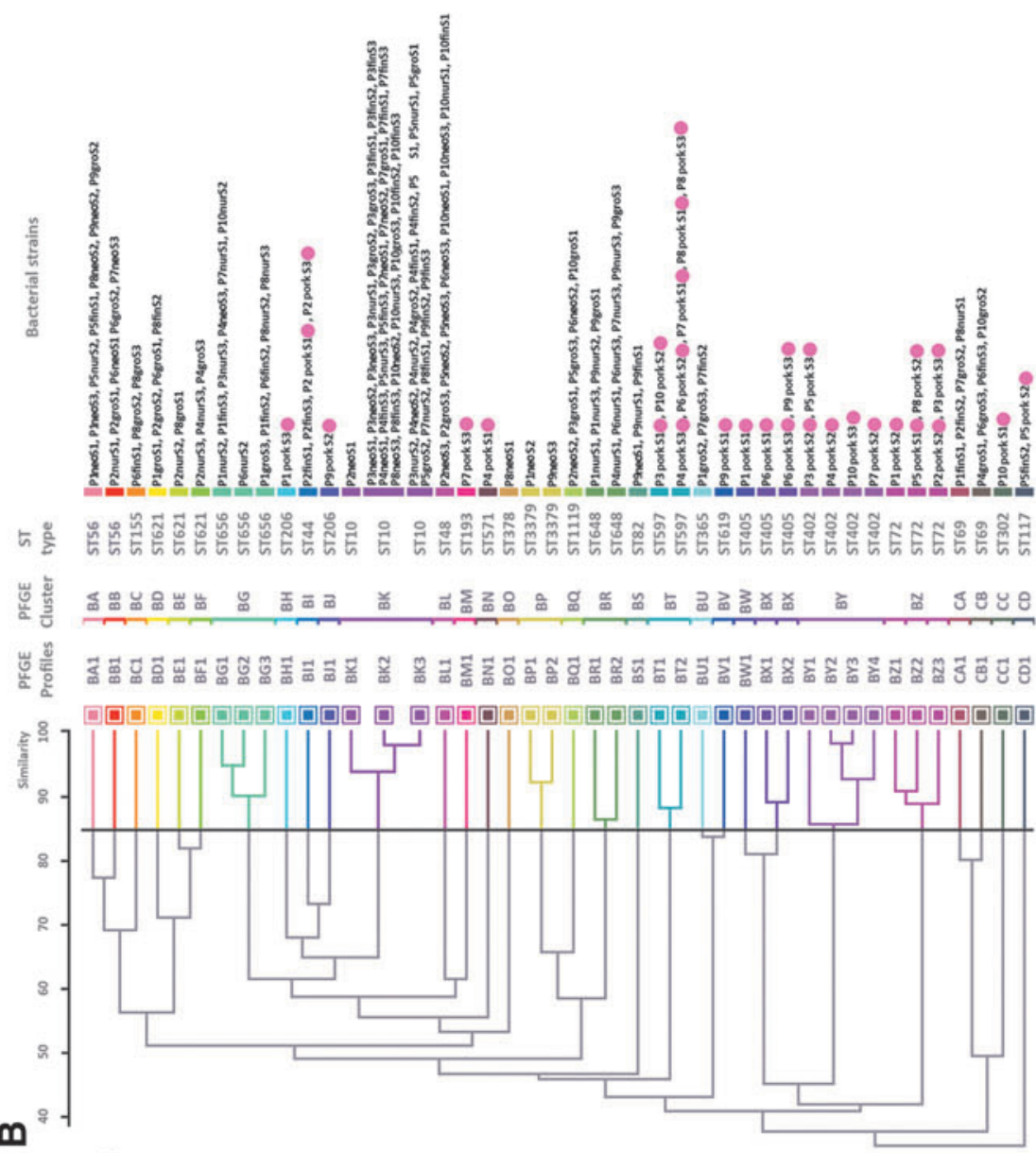

छี

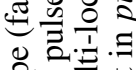

丠

톤들

응

on

元告

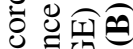

U

चु

웡멩

की

疑 윙

矛它送

政

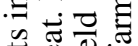

气 すす

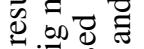

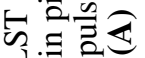

刍

흐을

3 니

政

㐘㐘

떵를

讨

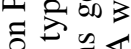

o 过

可 해요

을

픙

중조

踝可

है क웡

행들 줄

흘

ष《

字的的

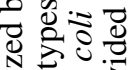

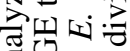

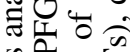

的会

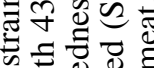

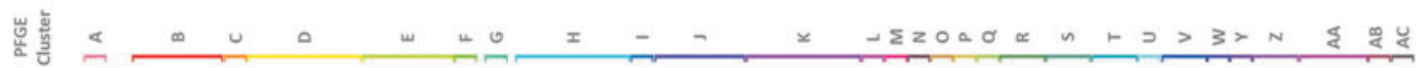

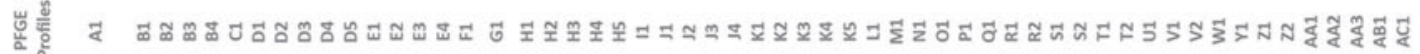

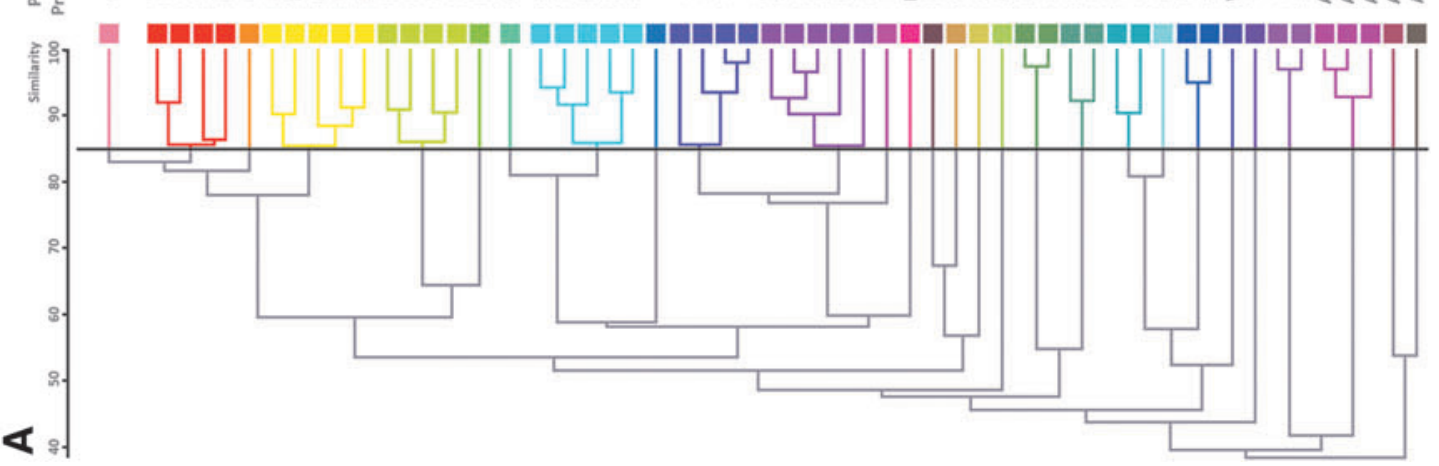

$\approx \overline{3}=0$

$<\ll$

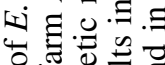

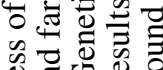

ڤั

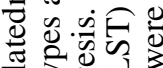

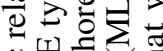

넹 응 on

可记

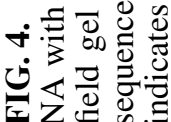




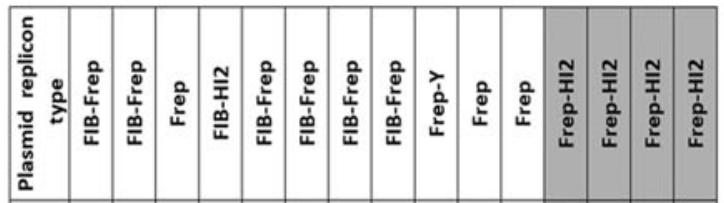

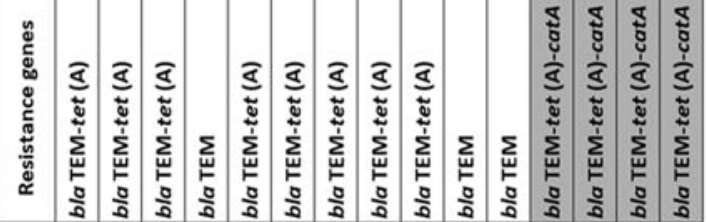

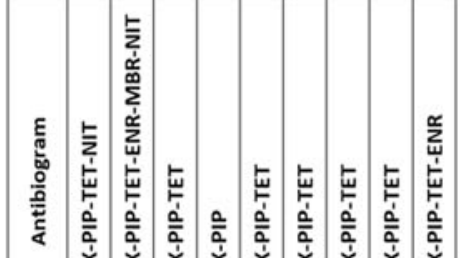

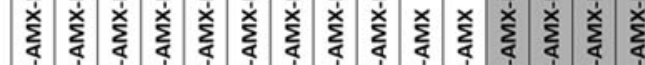

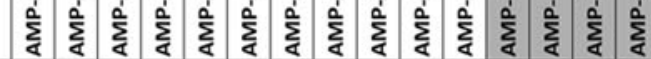

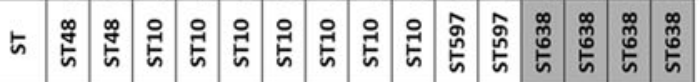

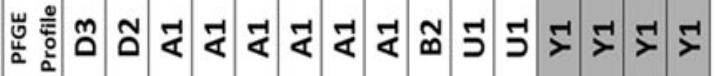

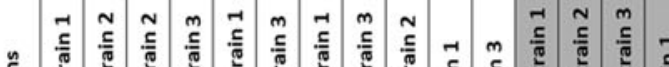

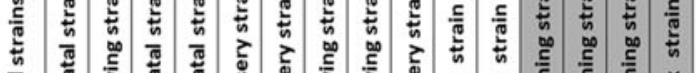

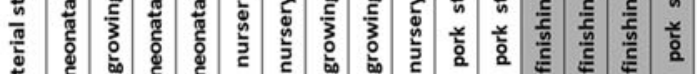

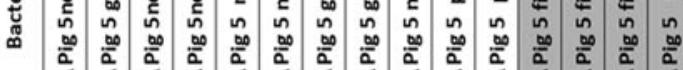

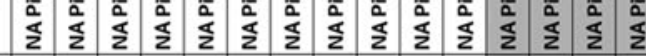
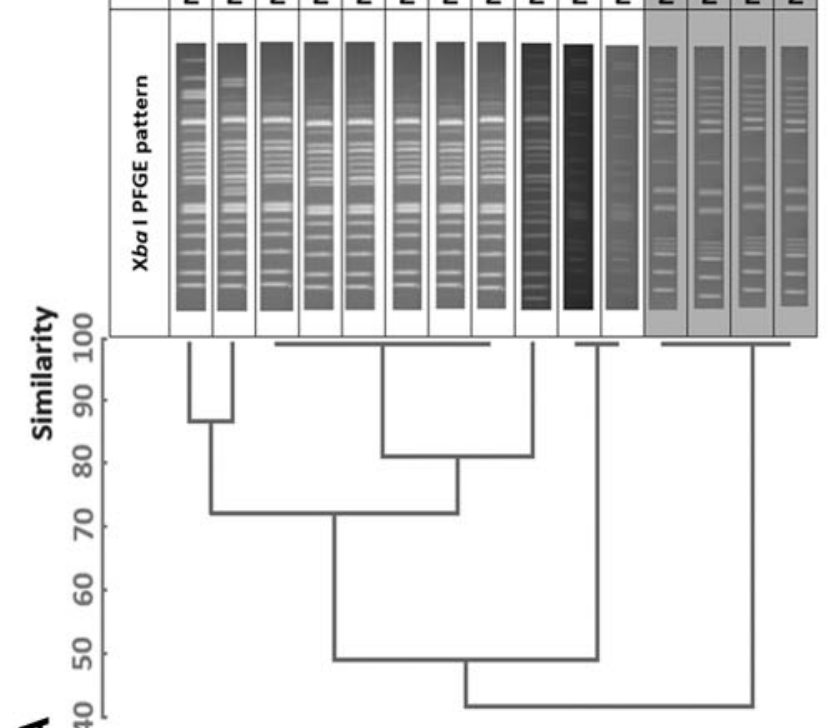

In

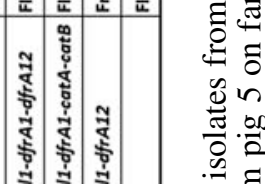

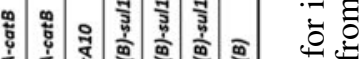

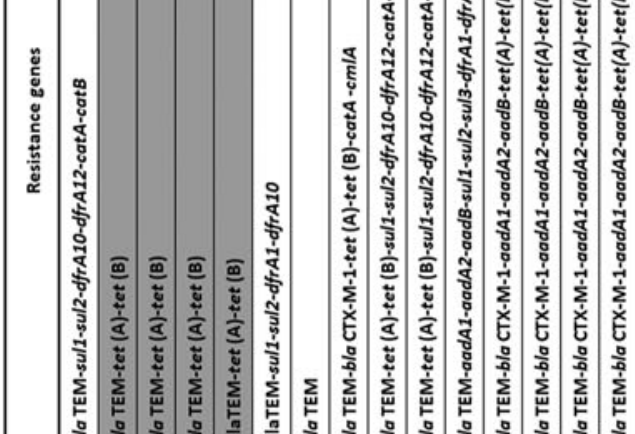

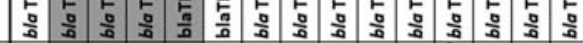

|

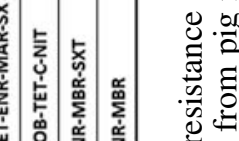

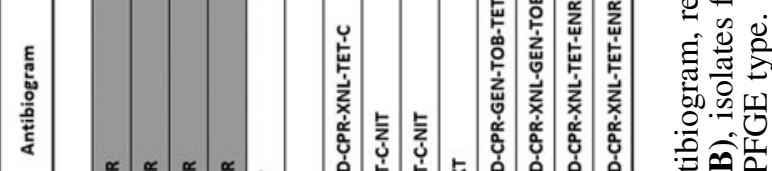

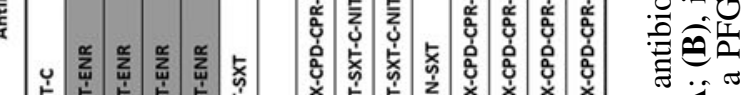

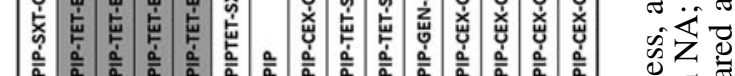

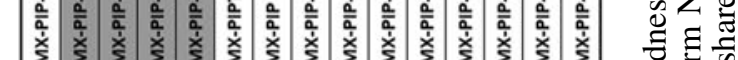

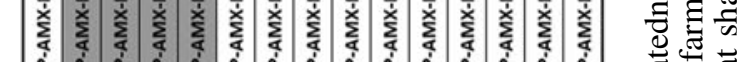

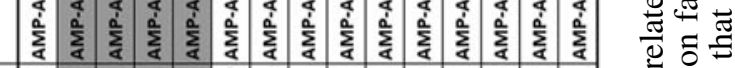

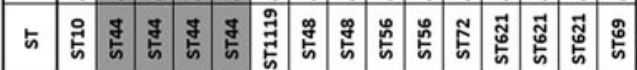

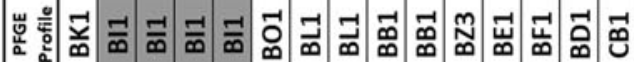

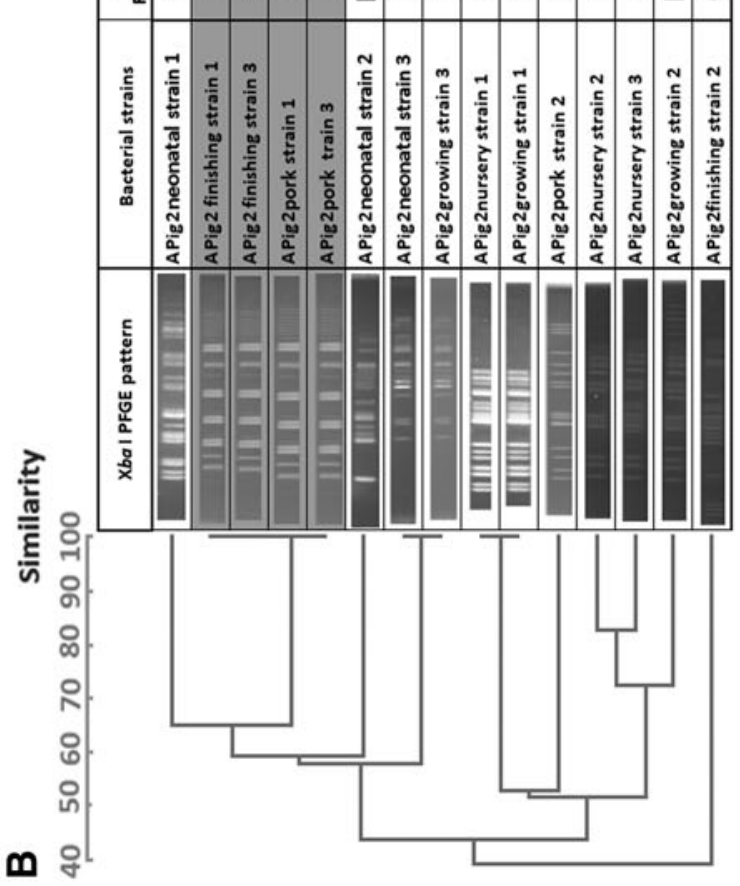
.0

वे ह

$\infty$

$\underset{\Xi}{ \pm}$

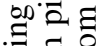

淧

$\frac{2}{\omega} \frac{\infty}{0}$

.

0

焉离

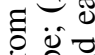

远政

密宩

$\because \frac{0}{0}$ 品

¿

过芯芯章

里.

过

萼.

的莽

نे 

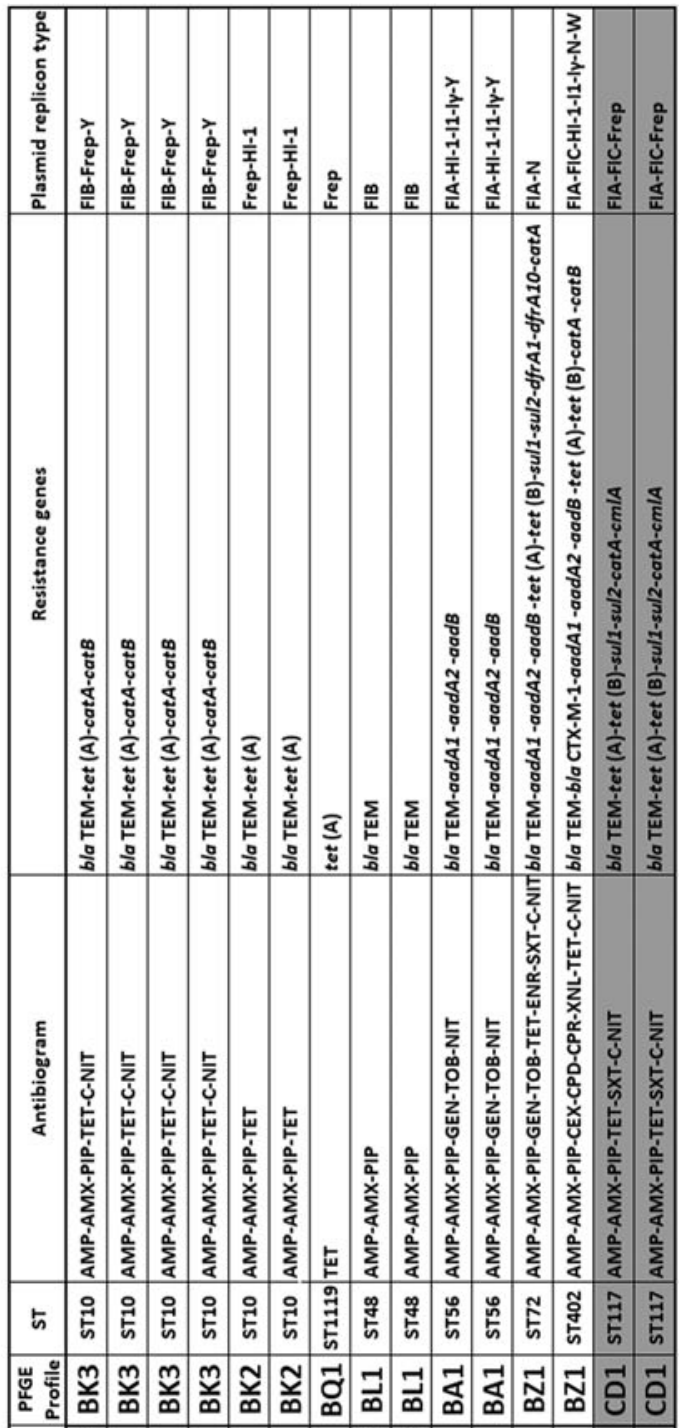

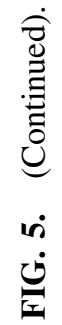

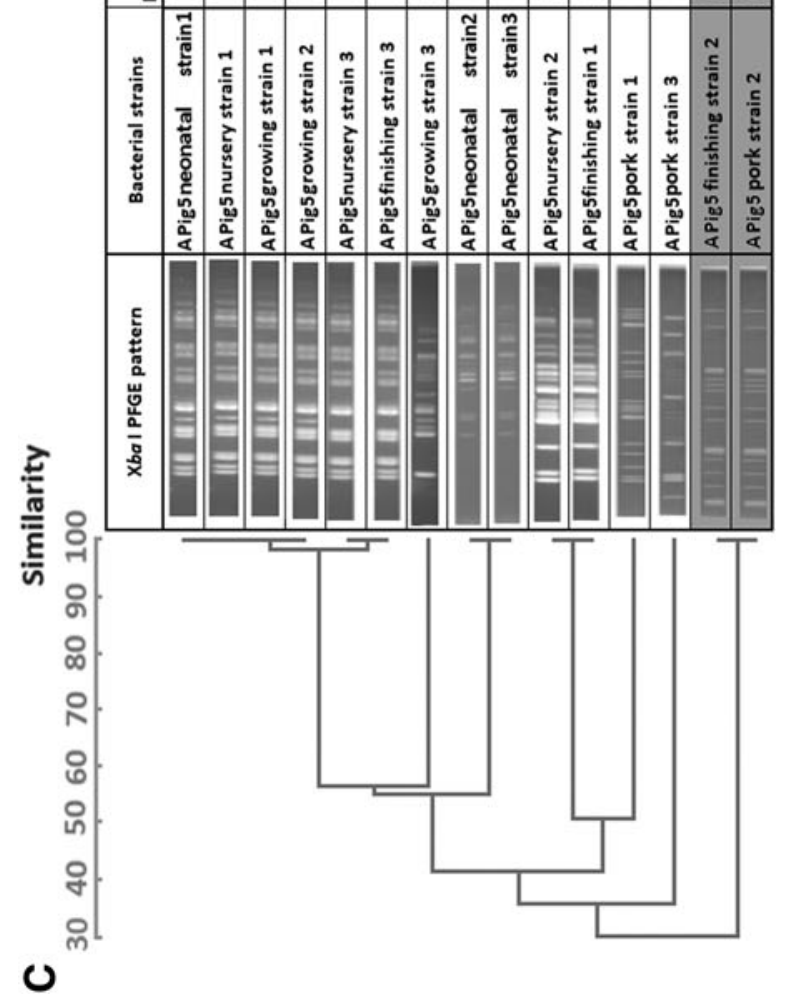


and two on farm A (ST638 and ST117) (Fig. 5 and Supplementary Table S1; Supplementary Data are available online at www.liebertpub.com/mdr). These shared strains did not show the ESBLP trait or aminoglycoside resistance. Sharing of strains with exactly the same characteristics between live pigs and pork was not found for the other 17 pigs.

For the 100 sampling activities, there were only 11 instances where the STs of the three isolates taken from the same pig were the same (Supplementary Table S1). Eight of these 11 instances were in pigs from farm NA and three from farm A. Nine of the incidences involved ST10, with the other two being ST638 and ST597. In 40 cases, two of the three isolates had the same ST (19 on farm NA and 21 on farm A), and in the other 49 cases, three different isolates were recovered.

Figure 6 presents a synopsis of the relationships of E. coli isolates at each production period and in pork, based on their STs. Although ST10 was not found in pork, it was the most common type found in live animals from both farms (57/150 from farm NA and 40/150 from farm A). The difference in rates for ST10 between the two farms was significant $(p<0.05)$. In nearly every case, the isolates from pork belonged to different STs from those in the live pigs: as previously mentioned, exceptions were ST638 in farm NA, and ST44 and ST117 in farm A. Of the 12 STs that included isolates recovered from pork, six had isolates with ESBLP characteristics (ST302, ST402, ST604, ST877, ST1209, and ST2798). These isolates were only found in pork, and four of the STs were only isolated from the NA farm. ST597 did not show ESBLP characteristics, but it was of interest because although it was not found in live pigs, it was common in pork derived from pigs from both farms. STs containing isolates with ESBLP characteristics did occur in pigs on farm NA, but such strains were more common and sometimes also associated with aminoglycoside resistance in pigs on farm A.

\section{Discussion}

Even though it is understood that commensal bacteria in animals may act as a reservoir of AMR, to date, evidence verifying a direct link between these organisms in livestock and their occurrence in meat products is limited. ${ }^{22}$ This study sought further evidence by undertaking longitudinal monitoring of AMR in commensal E. coli isolated from cohorts of pigs sampled at different stages of the pig production cycle, and comparing these to isolates from meat taken from the same animals after slaughter. Meat rather than feces was sampled postslaughter, as this is the product to which consumers are exposed. The design of the study was not able to account for any potential postslaughter cross-contamination of carcasses by E. coli strains during their handling and processing before sampling occurred.

The study examined susceptibility to large numbers of different antimicrobials, including consideration of ESBLP and aminoglycoside resistance because of the high significance of these traits for human bacterial infections. In this study, as in a previous study, ${ }^{9}$ aminoglycoside resistance rates and the presence of aminoglycoside resistance genes (aadA1, aadA2, and $a a d B$ ) significantly increased, but only in the nursery and grower phases, and only on farm A. Hence the routine use of unrelated antimicrobials increased resistance to these critically important antimicrobials in growing animals. ${ }^{9,23}$ The reason(s) for this remain unclear, but may be due to some form of co-selection. Although AMR was common, and resistance to $\beta$-lactam group antibiotics and tetracycline were again found in most isolates, the resistance rates in isolates from fattening pigs for cefalexin, cefpirome, cefpodoxime, ceftiofur, chloramphenicol, enrofloxacin, gentamicin, imipenem, marbofloxacin, nitrofurantoin, tobramycin, trimethoprim/sulfamethoxazole, and ESBLP E. coli were lower than in a previous study in Thailand. ${ }^{9}$ This difference was presumably due to farmspecific factors, as the laboratory methods used in the two studies were the same.

To add another dimension to this study, two farms were followed, with one routinely using in-feed antimicrobials and the other not doing this. Previously we have shown that this routine in-feed antimicrobial use increases AMR rates in commensal E. coli in fattening pigs in Thailand, ${ }^{9}$ and hence we hypothesized that pork from farms using infeed antimicrobials might be more heavily contaminated with AMR commensal bacteria following slaughter compared to farms not using antimicrobials. Nevertheless, in this study, no significant differences were found in AMR rates in isolates from pork from the two farms. Routine antimicrobial use on farm A only significantly increased resistance rates to aminoglycosides and the presence of ESBLP E. coli, and only in the nursery and grower periods.

In general, farm management and geographical origin have been shown to influence genetic diversity and the presence of AMR genes found in porcine $E$. coli isolates. ${ }^{24}$ In previous studies, a high clonal diversity of $E$. coli in pigs has been shown to occur both at the individual and pen levels ${ }^{25}$ although individual strains may come to dominate. For example, in one recent cross-sectional study in a Danish pig farm not using antimicrobials, E. coli strains of ST10 and ST58 commonly were recovered throughout the growing period. ${ }^{20}$ In this study, three colonies from a high dilution $\left(10^{-4}\right)$ of each sample were selected for analysis to enhance the recruitment of a variety of $E$. coli strains. ${ }^{9,26}$ Using this sampling method, ST10 was the major type found in live animals in both farms, but it was not found in pork meat. ST10 E. coli also has been reported in humans, chickens, and other animals. ${ }^{27,28}$ In contrast to ST10, ST597 was the most common type found in pork from both farms, but it was not identified in live animals. It also was not ESBLP or resistant to aminoglycosides. ST597 could have been a cross-contaminant from the environment of the abattoir, from equipment, or from other carcasses, although the pigs from the two farms were killed in different abattoirs and so no single external source existed. ST597 has been reported as an enteric foodborne pathogen in humans ${ }^{29}$ so identifying the route for its appearance in pig meat in abattoirs is important. Further studies into transmission of E. coli with AMR characteristics in the food chain are required: in particular, Hazard Analysis and Critical Control Points should be applied during farm to abattoir transportation, and through the standard slaughtering process, meat trimming, and packaging. The dominant $E$. coli types found in meat may have attributes that could help to explain why they are present rather than other types found in live animals.

As anticipated, molecular tracing and evaluation of strain relationships using MLST and PFGE gave similar results. ${ }^{30}$ 


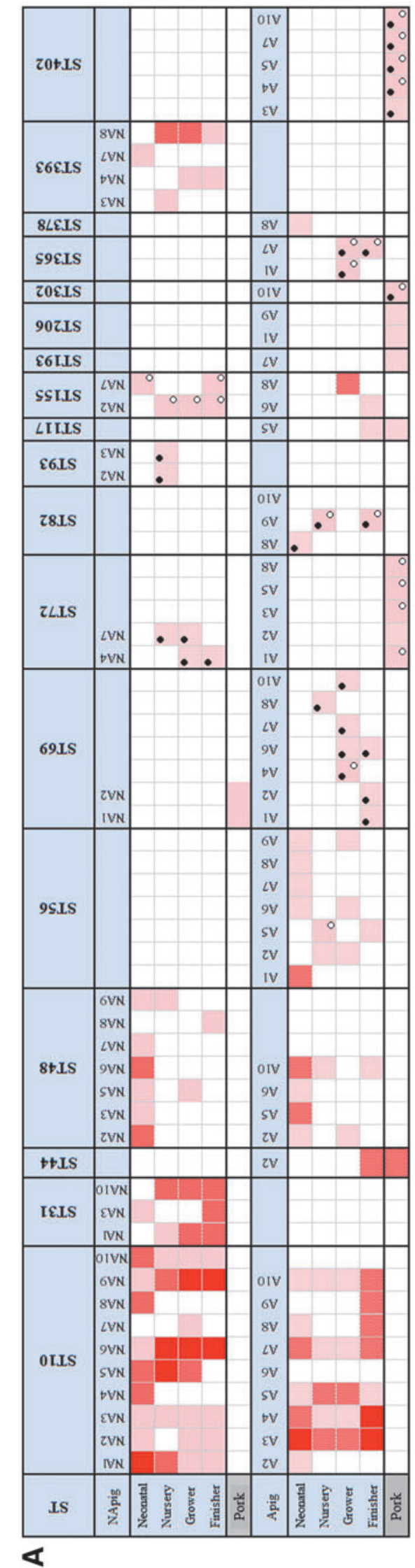

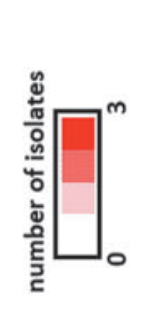

\section{\begin{tabular}{|l|l|}
\hline $86 I+I S$ & $8 \mathrm{VN}$ \\
\hline
\end{tabular}}

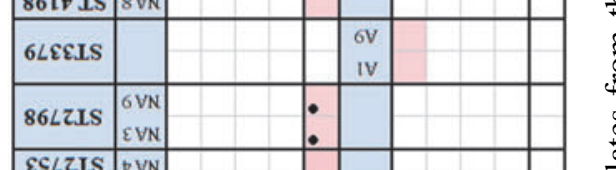

$$
\begin{array}{|l}
\mathcal{E} S \mathrm{~L} \\
\hline \mathcal{E} \varepsilon \\
\hline
\end{array}
$$
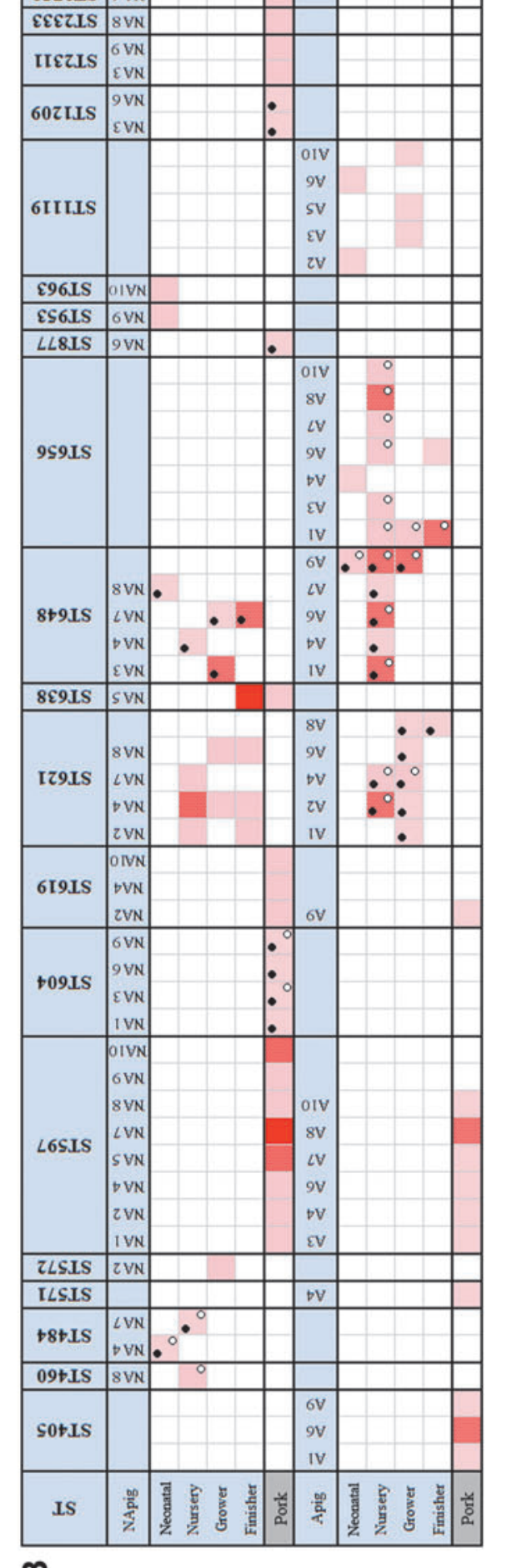

$\boldsymbol{m}$

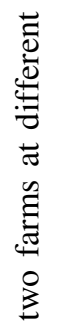

$\stackrel{0}{ \pm}$

号

离 :

$\approx \frac{\pi}{5}$

더 응

유. ह

灵

ช.

.

可哈

으.

08

of 0

䍂

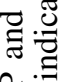

จิะ

雳

पั

ธี

:

苟人i

再

สิ

的至

눙

ㄱ.

ए

항

$\stackrel{0}{ \pm}$

$\cong$

넝

.

.$\frac{3}{0}$

․ำ

范

-

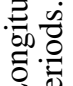

$-2$

๑. 谣 
Most $E$. coli types in pork were not detected in live pigs, except for STs 44, 117, 155, and 638 that included nonESBPL E. coli and were negative for $b l a_{\mathrm{CTX}-\mathrm{M}}$ genes. As with previous cross-sectional surveys, no relationship was found between molecular types that contained genes encoding ESBLP and aminoglycoside resistance on the farm and their presence in the abattoir. ${ }^{31}$

Resistance to amino-penicillins (ampicillin and amoxicillin) and urevido-penicillin (piperacillin) conferred by the $b l a_{\text {TEM }}$ gene and tetracycline resistance conferred by the tet $(\mathrm{A})$ gene were the most common forms of AMR in both farms at all observation periods, and was consistent with results of previous cross-sectional studies in Southeast Asia. $^{32}$ The persistence of bla ${ }_{\text {TEM }}$ and tet(A) genes in E. coli may not be caused by direct selective pressure, but may imply an abundance of bla $a_{\text {TEM }}$ and tet(A) genes in Enterobacteriaceae bacteria in the region. ${ }^{33}$ Despite cephalosporins and aminoglycosides not being used on the farms, ESBLP E. coli containing bla CTX-M-1 group $_{\text {and }}$ aminoglycoside-resistant $E$. coli containing aadA1, aadA2, and $a a d B$ were common in the nursery period in farm A. This confirmed the findings of our previous study ${ }^{9}$ and might be explained by a co-harboring of multiresistance genes, including $c f r$ and $b l a_{\mathrm{CTX}-\mathrm{M}}$ genes, on a conjugative plasmid. $^{34}$

Replicons IncFrep and IncFIB are reported as the most common types found in E. coli from humans and animals, and this was seen in both groups in this study. These plasmids, which encode factors involved in iron uptake, toxin production, enzymes, and a variety of resistance genes, for example, bla $a_{\text {CTX-M }}$, are widely spread in Enterobacteriaceae. ${ }^{35}$ In farm A, the high frequency of IncI1-I $\gamma$, IncHI2, in E. coli in the nursery period was strongly correlated with the detection of ESBLP and the $b l a_{\mathrm{CTX}-\mathrm{M}-1}$ group gene. In previous studies, IncHI2 was found to carry not only the $b l a_{\mathrm{CTX}-\mathrm{M}-2}$ gene but also a variety of genes encoding sulfonamide, aminoglycoside, tetracycline, and streptomycin resistance. ${ }^{36}$ IncI1-I $\gamma$ carrying $b l a_{\mathrm{CTX}-\mathrm{M}-1}$ is also the most common plasmid found in E. coli from livestock. ${ }^{37}$ Thus, the nursery and grower pigs from farm A could act as an important reservoir of AMR on the farm, and possibly have an impact on public health by amplifying resistance genes that eventually make their way to other zoonotic pathogens or to the environment.

In conclusion, commensal E. coli with AMR traits (especially resistance to $\beta$-lactam group antibiotics and tetracycline) were common in pigs from both farms at all sampling periods. E. coli that were aminoglycoside resistant and ESBLP were commonly found in the nursery and grower periods, and were significantly more common in the farm that routinely used unrelated classes of antibiotics. Molecular typing showed that on both farms, strains from pigs and pork were different in terms of their clonal types and characteristics. This suggests that on-farm resistance, which is encouraged by antimicrobial usage, does not necessarily reflect the attributes of $E$. coli found in meat at the abattoir. Further work is required to identify potential sources of resistant $E$. coli found in pig meat following slaughter.

\section{Acknowledgments}

This study was supported financially by the 90th Year Anniversary Ratchdapisek Somphot Endowment Fund,
Chulalongkorn University, Center of Excellence in Emerging and Re-emerging Infectious Diseases in Animals (EIDAs), Research and Researcher for Industrials Funds (PHD5610005), and Huvepharma (Thailand) Ltd.

\section{Disclosure Statement}

No competing financial interests exist.

\section{References}

1. Huttner, A., S. Harbarth, J. Carlet, S. Cosgrove, H. Goossens, A. Holmes, V. Jarlier, A. Voss, and D. Pittet. 2013. Antimicrobial resistance: a global view from the 2013 World Healthcare-Associated Infections Forum. Antimicrob. Resist Infect. Control. 2:31.

2. Kaspar, H. 2006. Results of the antimicrobial agent susceptibility study raised in a representative, cross-sectional monitoring study on a national basis. Int. J. Med. Microbiol. 296 Suppl 41:69-79.

3. Lhermie, G., Y.T. Grohn, and D. Raboisson. 2016. Addressing Antimicrobial Resistance: an Overview of Priority Actions to Prevent Suboptimal Antimicrobial Use in FoodAnimal Production. Front. Microbiol. 7:2114.

4. Burow, E., C. Simoneit, B.A. Tenhagen, and A. Kasbohrer. 2014. Oral antimicrobials increase antimicrobial resistance in porcine E. coli-a systematic review. Prev. Vet. Med. 113:364-375.

5. Fernandes, L., M.M. Centeno, N. Couto, T. Nunes, V. Almeida, L. Alban, and C. Pomba. 2016. Longitudinal characterization of monophasic Salmonella Typhimurium throughout the pig's life cycle. Vet. Microbiol. 192: 231-237.

6. Renoux, G., and A. Terdjman. 1951. Clinical value of the precise identification of gram-negative urinary bacilli; practical value of the medium eosine-methylene blue (E.M.B.). Presse. Med. 59:203-206.

7. Demarco, D.R., and D.V. Lim. 2002. Detection of Escherichia coli $\mathrm{O} 157: \mathrm{H7}$ in 10- and 25-gram ground beef samples with an evanescent-wave biosensor with silica and polystyrene waveguides. J. Food. Prot. 65:596-602.

8. Clark, H.F., E.E. Geldreich, P.W. Kabler, R.H. Bordner, and C.B. Huff. 1957. The coliform group. I. The boric acid lactose broth reaction of coliform IMViC types. Appl. Microbiol. 5:396-400.

9. Lugsomya, K., T. Chatsuwan, W. Niyomtham, P. Tummaruk, D.J. Hampson, and N. Prapasarakul. 2018. Routine prophylactic antimicrobial use is associated with increased phenotypic and genotypic resistance in commensal Escherichia coli isolates recovered from healthy fattening pigs on farms in Thailand. Microb. Drug Resist. 24:213-223.

10. CLSI. 2015. Performance Standards for Antimicrobial Disk and Dilution Susceptibility test for Bacteria Isolated From Animals; 3rd VET01-S3. Clinical and Laboratory Standards Institute, Wayne, PA.

11. CLSI. 2015. Performance Standards for Antimicrobial Susceptibility Testing; 24th Informational Supplement. M100-S25. Clinical and Laboratory Standards Institute, Wayne, PA.

12. Espinar, M.J., R. Rocha, M. Ribeiro, A. Goncalves Rodrigues, and C. Pina-Vaz. 2011. Extended-spectrum beta-lactamases of Escherichia coli and Klebsiella pneumoniae screened by the VITEK 2 system. J. Med. Microbiol. 60:756-760. 
13. Xu, L., V. Ensor, S. Gossain, K. Nye, and P. Hawkey. 2005. Rapid and simple detection of $b l a_{\mathrm{CTX}-\mathrm{M}}$ genes by multiplex PCR assay. J. Med. Microbiol. 54:1183-1187.

14. Kumar, S., G. Stecher, and K. Tamura. 2016. MEGA7: molecular evolutionary genetics analysis version 7.0 for bigger datasets. Mol. Biol. Evol. 33:1870-1874.

15. Gray, K.J., L.K. Wilson, A. Phiri, J.E. Corkill, N. French, and C.A. Hart. 2006. Identification and characterization of ceftriaxone resistance and extended-spectrum beta-lactamases in Malawian bacteraemic Enterobacteriaceae. J. Antimicrob. Chemother. 57:661-665.

16. Chuanchuen, R., K. Ajariyakhajorn, C. Koowatananukul, W. Wannaprasat, S. Khemtong, and S. Samngamnim. 2010. Antimicrobial resistance and virulence genes in Salmonella enterica isolates from dairy cows. Foodborne Pathog. Dis. 7:63-69.

17. Carattoli, A., A. Bertini, L. Villa, V. Falbo, K.L. Hopkins, and E.J. Threlfall. 2005. Identification of plasmids by PCRbased replicon typing. J. Microbiol. Methods. 63:219-228.

18. CDC. 2013. Standard Operating Procedure for PulseNet PFGE of Escherichia coli O157:H7, Escherichia coli nonO157 (STEC), Salmonella serotypes, Shigella sonnei and Shigella flexneri. 13. Available at www.pulsenetinternational .org/assets/PulseNet/uploads/pfge/PNL05_Ec-Sal-ShigPFGE protocol.pdf

19. Adiri, R.S., U. Gophna, and E.Z. Ron. 2003. Multilocus sequence typing (MLST) of Escherichia coli O78 strains. FEMS. Microbiol. Lett. 222:199-203.

20. Boers, S.A., W.A. van der Reijden, and R. Jansen. 2012. High-throughput multilocus sequence typing: bringing molecular typing to the next level. PLoS One 7:e39630.

21. Ahmed, S., J.E. Olsen, and A. Herrero-Fresno. 2017. The genetic diversity of commensal Escherichia coli strains isolated from non-antimicrobial treated pigs varies according to age group. PLoS One. 12:e0178623.

22. Thorsteinsdottir, T.R., G. Haraldsson, V. Fridriksdottir, K.G. Kristinsson, and E. Gunnarsson. 2010. Prevalence and genetic relatedness of antimicrobial-resistant Escherichia coli isolated from animals, foods and humans in Iceland. Zoonoses Public Health. 57:189-196.

23. WHO. 2016. Critically Important Antimicrobials for $\mathrm{Hu}-$ man Medicine Geneva Switzerland 5th revision 2016. WHO, Geneva, pp. 1-48.

24. Leistner, R., E. Meyer, P. Gastmeier, Y. Pfeifer, C. Eller, P. Dem, and F. Schwab. 2013. Risk factors associated with the community-acquired colonization of extended-spectrum beta-lactamase (ESBL) positive Escherichia Coli an exploratory case-control study. PLoS One. 8:e74323.

25. Herrero-Fresno, A., S. Ahmed, M.H. Hansen, M. Denwood, C. Zachariasen, and J.E. Olsen. 2017. Genotype variation and genetic relationship among Escherichia coli from nursery pigs located in different pens in the same farm. BMC Microbiol. 17:5.

26. Lautenbach, E., W.B. Bilker, P. Tolomeo, and J.N. Maslow. 2008. Impact of diversity of colonizing strains on strategies for sampling Escherichia coli from fecal specimens. J. Clin. Microbiol. 46:3094-3096.

27. Leverstein-van Hall, M.A., C.M. Dierikx, J. Cohen Stuart, G.M. Voets, M.P. van den Munckhof, A. van EssenZandbergen, T. Platteel, A.C. Fluit, N. van de SandeBruinsma, J. Scharinga, and others. 2011. Dutch patients, retail chicken meat and poultry share the same ESBL genes, plasmids and strains. Clin. Microbiol. Infect. 17:873-880.
28. Toval, F., C.D. Kohler, U. Vogel, F. Wagenlehner, A. Mellmann, A. Fruth, M.A. Schmidt, H. Karch, M. Bielaszewska, and U. Dobrindt. 2014. Characterization of Escherichia coli isolates from hospital inpatients or outpatients with urinary tract infection. J. Clin. Microbiol. 52:407-418.

29. Khong, W.X., E. Xia, K. Marimuthu, W. Xu, Y.Y. Teo, E.L. Tan, S. Neo, P.U. Krishnan, B.S. Ang, D.C. Lye, and others. 2016. Local transmission and global dissemination of New Delhi Metallo-Beta-Lactamase (NDM): a whole genome analysis. BMC Genomics. 17:452.

30. Nemoy, L.L., M. Kotetishvili, J. Tigno, A. Keefer-Norris, A.D. Harris, E.N. Perencevich, J.A. Johnson, D. Torpey, A. Sulakvelidze, J.G. Morris, Jr. and others. 2005. Multilocus sequence typing versus pulsed-field gel electrophoresis for characterization of extended-spectrum beta-lactamaseproducing Escherichia coli isolates. J. Clin. Microbiol. 43: 1776-1781.

31. Sunde, M., G.S. Simonsen, J.S. Slettemeas, I. Bockerman, and M. Norstrom. 2015. Integron, Plasmid and Host Strain Characteristics of Escherichia coli from Humans and Food Included in the Norwegian Antimicrobial Resistance Monitoring Programs. PLoS One. 10:e0128797.

32. Nhung, N.T., N.V. Cuong, G. Thwaites, and J. CarriqueMas. 2016. Antimicrobial Usage and Antimicrobial Resistance in Animal Production in Southeast Asia: a Review. Antibiotics. (Basel) 5: pii: E37.

33. Honda, R., T. Watanabe, V. Sawaittayotin, Y. Masago, R. Chulasak, K. Tanong, G.T. Chaminda, K. Wongsila, C. Sienglum, V. Sunthonwatthanaphong, and others. 2016. Impacts of urbanization on the prevalence of antibioticresistant Escherichia coli in the Chaophraya River and its tributaries. Water. Sci. Technol. 73:362-374.

34. Zhang, W.J., X.M. Wang, L. Dai, X. Hua, Z. Dong, S. Schwarz, and S. Liu. 2015. Novel conjugative plasmid from Escherichia coli of swine origin that coharbors the multiresistance gene $c f r$ and the extended-spectrum-beta-lactamase gene $b l a_{\mathrm{CTX} \text {-M- }}$ 14b. Antimicrob. Agents. Chemother. 59:1337-1340.

35. Rozwandowicz, M., M.S.M. Brouwer, J. Fischer, J.A. Wagenaar, B. Gonzalez-Zorn, B. Guerra, D.J. Mevius, and J. Hordijk. 2018. Plasmids carrying antimicrobial resistance genes in Enterobacteriaceae. J. Antimicrob. Chemother. 73: 1121-1137

36. Dierikx, C., A. van Essen-Zandbergen, K. Veldman, H. Smith, and D. Mevius. 2010. Increased detection of extended spectrum beta-lactamase producing Salmonella enterica and Escherichia coli isolates from poultry. Vet. Microbiol. 145:273-278.

37. Borjesson, S., B. Bengtsson, C. Jernberg, and S. Englund. 2013. Spread of extended-spectrum beta-lactamase producing Escherichia coli isolates in Swedish broilers mediated by an incl plasmid carrying $b l a_{\mathrm{CTX}-\mathrm{M}-1}$. Acta. Vet. Scand. 55:3.

Address correspondence to: Nuvee Prapasarakul, DVM, PhD Department of Veterinary Microbiology Faculty of Veterinary Science Chulalongkorn University Pathumwan District Henri-Dunant Street Bangkok 10330 Thailand

E-mail: nuvee.p@chula.ac.th 